\title{
Nanoporous Glasses for Nuclear Waste Containment
}

\author{
Thierry Woignier, ${ }^{1,2}$ Juan Primera, ${ }^{3,4}$ and Jerôme Reynes ${ }^{5}$ \\ ${ }^{1}$ Aix Marseille Université, Université d'Avignon, CNRS, IRD, IMBE, 13397 Marseille, France \\ ${ }^{2}$ IRD-Campus Agro Environnemental Caraïbes, Le Lamentin, 97232 Martinique, France \\ ${ }^{3}$ Departamento de Fisica, FEC, LUZ, Maracaibo 4011, Venezuela \\ ${ }^{4}$ Escuela Superior Politécnica del Litoral (ESPOL), Facultad de Ciencias Naturales y Matemáticas, Departamento de Física, \\ Campus Gustavo Galindo, Km 30.5 Vía Perimetral, P.O. Box 09-01-5863, 090150 Guayaquil, Ecuador \\ ${ }^{5}$ Laboratoire Charles Coulomb, Université Montpellier 2, Place E. Bataillon, 34095 Montpellier Cedex 5, France
}

Correspondence should be addressed to Thierry Woignier; thierry.woignier@univ-montp2.fr

Received 25 February 2016; Revised 23 June 2016; Accepted 10 July 2016

Academic Editor: Mahaveer Kurkuri

Copyright (c) 2016 Thierry Woignier et al. This is an open access article distributed under the Creative Commons Attribution License, which permits unrestricted use, distribution, and reproduction in any medium, provided the original work is properly cited.

Research is in progress to incorporate nuclear waste in new matrices with high structural stability, resistance to thermal shock, and high chemical durability. Interactions with water are important for materials used as a containment matrix for the radio nuclides. It is indispensable to improve their chemical durability to limit the possible release of radioactive chemical species, if the glass structure is attacked by corrosion. By associating high structural stability and high chemical durability, silica glass optimizes the properties of a suitable host matrix. According to an easy sintering stage, nanoporous glasses such as xerogels, aerogels, and composite gels are alternative ways to synthesize silica glass at relatively low temperatures $\left(\approx 1,000-1,200^{\circ} \mathrm{C}\right)$. Nuclear wastes exist as aqueous salt solutions and we propose using the open pore structure of the nanoporous glass to enable migration of the solution throughout the solid volume. The loaded material is then sintered, thereby trapping the radioactive chemical species. The structure of the sintered materials (glass ceramics) is that of nanocomposites: actinide phases $(\sim 100 \mathrm{~nm})$ embedded in a vitreous silica matrix. Our results showed a large improvement in the chemical durability of glass ceramic over conventional nuclear glass.

\section{Introduction}

A number of materials have been considered to incorporate hazardous nuclear wastes such as ceramics, cements, metal matrices, and glasses [1-8]. Presently, the two best candidate materials are crystalline ceramics and glasses. Fixation of radioactive wastes in glasses has been shown to be a viable technological alternative for effective management of nuclear wastes. The advantages of the method are that a large number of elements can be incorporated into the glass structure and a small volume of solid waste is produced as a result [9]. In this process, the radioactive elements are mixed and melted with a glass frit [10]. However, to ensure long-term storage, long-life nuclear waste (actinides) has to be incorporated in a matrix with excellent chemical durability $[11,12]$. Research is in progress to propose new matrices with high structural stability, good mechanical properties, and high chemical durability. Titania-based minerals and zirconia-based glass ceramics, in which the crystalline phases are embedded in an aluminosilicate glass matrix, are possible candidates [35]. They consist of a highly durable crystalline phase homogeneously dispersed in a glass matrix that also has good chemical durability [6-8]. The titanite and zirconolite phases suggest that these matrices are highly corrosion resistant.

The properties of silica glasses, including good durability and mechanical strength and the ability to incorporate large concentrations of dopants, make them ideal candidates as matrices for the storage of nuclear waste. The main disadvantage of silica glasses for this kind of use is their high processing temperature of $\sim 2,000^{\circ} \mathrm{C}$. However, it has been shown that the sol-gel process is an appropriate low temperature process to obtain glasses at around $1,000^{\circ} \mathrm{C}$, not by melting but by sintering of a nanoporous amorphous silica gel [1320]. In this paper, we compare different nanoporous silica 
networks as possible host matrices for actinides and assess the feasibility of fixing actinides in silica glass. We characterize different families of porous glasses and examine the advantages and drawbacks of the different porous matrices. We focus on the mechanical properties and the permeability of the porous materials. These features depend on the pore volume, which can be adjusted using different parameters and processes including silica content, sintering, drying, and composite approach.

\section{State of the Art}

2.1. Porous Glasses by Foaming or Leaching of Glasses. The classical procedure for making glass includes a high temperature step that ensures that the raw materials are dissolved and have reacted. At that point, the amorphous structure of the liquid is preserved by quenching the melt. Standard glass is generally the result of a multistep process including melting the different oxides at a high temperature followed by refining and finally quenching. One possible way to prepare porous glass is to nucleate the bubbles inside the melt and then to quench it. The resulting glass is generally called "foamed glass" [21, 22]. The bubbles are obtained through the decomposition of carbonates during melting, but this process is not suitable for the preparation of high durability glass for the fixation of nuclear wastes. Another example of porous glass obtained in the standard way is microphase separated and leached "Vycor" glass [14, 23-25]. In this process, sodium borosilicate glass is heat-treated to induce phase separation. An acidic corrosion treatment will dissolve the "weak" borate phase and create continuous porosity in the silicate phase. The nanoporous glass can then be further sintered into vitreous silica glass at a temperature close to $1,200^{\circ} \mathrm{C}$, instead of the $2,000^{\circ} \mathrm{C}$ required by the standard procedure [25]. The authors of this precursor method were the first to suggest confining nuclear wastes in the porosity [14]. The nuclear waste was fixed in the porous structure, after which the pores are collapsed. However this kind of glass is not pure silica but contains 3-5 percent of boron [14]. As boron is much more soluble in water than silica, its presence reduces the chemical durability of the glass.

2.2. Standard Sol-Gel-Glass Route. The high temperature step in the melting process for glass is avoided when the sol-gel route is used. The first step is the formation of a gel which generally involves the hydrolysis reaction of an organometallic compound $\left(\mathrm{Si}(\mathrm{OR})_{4}\right)$, dissolved in alcohol in the presence of water. By condensation reactions, two silanol groups give rise to siloxane bonds ( $\mathrm{SiOSi}$ ) [13]. These two reactions lead to noncrystalline materials.

Different types of silica gels for the synthesis of glass are described in the literature $[13,15,19,20,26,27]$. However, for impregnation experiments, the porous network has to be able to resist capillary stresses during the soaking steps. In porous materials, the mechanical properties depend on the load bearing fraction of the solid and decrease with an increase in pore volume [28]. On the other hand, pore volume increases permeability and improves waste loading [16]. A compromise is thus needed between the mechanical properties and

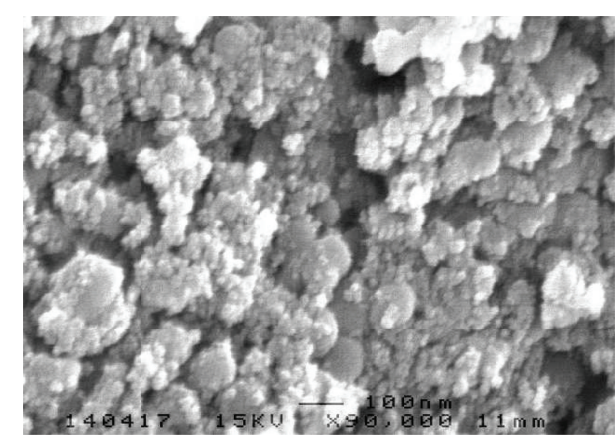

FIGURE 1: Scanning electron microscopy of xerogels.

permeability by controlling pore volume. The mechanical properties of the materials can be increased in different ways: (1) by collapsing the pore volume by drying, (2) by sintering, and (3) by using the composite approach.

2.3. Collapsing the Pore Volume. The result of gelation is a two-phase medium containing the solid network and the liquid (alcohol and water). Drying can be carried out at ambient temperature, but during the drying stage considerable shrinkage occurs which transforms the wet gel into a hard, dry, but nanoporous solid (pore range is close to $10 \mathrm{~nm}$ ) called "xerogel."

The drying procedure is crucial and must be extremely slow because otherwise it can lead to capillary phenomena that can destroy the gel network and break up the solid network. Alternative drying methods represent a favorable compromise between the capillary forces and the mechanical resistance of the gel network (strengthening the gel by reinforcement, reducing the surface tension, enlarging the pores, etc.) $[13,17]$. To summarize, xerogels samples can be synthesized by careful control of the drying parameters. Xerogels (Figure 1) are porous glasses whose pore volume ranges from 30 to $70 \%$ and which mainly comprise micropores due to the collapse of the larger pores.

2.4. Aerogels and Sintered Aerogels. The goal of supercritical drying is to eliminate these capillary forces. The magnitude of the stresses depends on the interfacial energy of the liquid, and it is possible to eliminate capillary stresses if the pressure and the temperature go beyond the critical point of the liquid $[29,30]$. The supercritical solvent is then isothermally evacuated by condensation outside the autoclave. After supercritical drying, the "aerogel" (Figure 2) is a solid material, amorphous but extremely porous (80-99\% porosity) and very brittle [29].

One (among others) possible application of these very porous materials is as a glass precursor. The silica aerogels can be easily transformed into silicate glasses by a sequence of sintering treatments $[15,26,31]$. Sintering enhances the mechanical properties of aerogels. Depending on the duration of the heat treatment, microporosity is progressively eliminated $[25,32]$. 


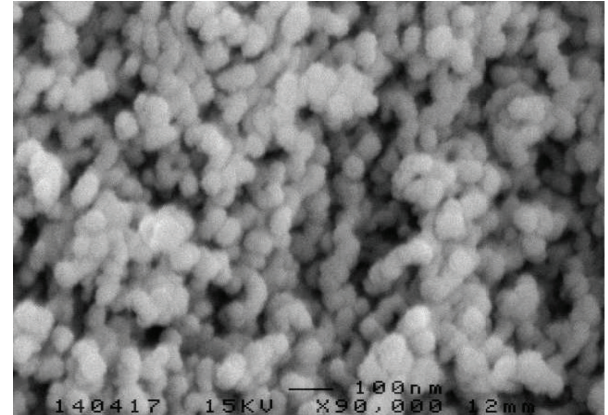

Figure 2: Scanning electron microscopy of aerogels.

2.5. The Composite Approach. Another important parameter is permeability. High permeability is usually an advantage because it means that the fluid and hence the chemical species of interest can easily migrate in the porous network and homogeneous distribution of the chemical species can be expected as a result. In ceramic science, it is generally accepted that the inclusion of particles or fibers improves the mechanical properties of composite ceramics and also modifies the porous structure (Figure 3). It is possible to adjust the density, the mechanical properties, the pore size distribution, and the permeability of the composite aerogels by adding silica powder (silica soot like aerosil OX50) to the monomer solution just before gelation $[15,31,33]$.

To summarize, mechanical properties, capillary forces, and permeability are the most important parameters for filling the nanoporous glass network. These different kinds of porous materials can all be considered nanoporous glass even though the "glassy" state is achieved in very different ways. They will be tested as host matrix for nuclear waste containment. The actinides are simulated by lanthanides nitrates $(\mathrm{Nd}$ and $\mathrm{Ce}$ ) in water, which diffuses by capillarity in the porous network. Guest molecules were deposited on the surface of the skeleton when the liquid was further evaporated. The mean pore size and the pore size distribution need to be tailored to facilitate homogeneous dispersion of doping molecules within the texture.

\section{Experimental}

3.1. Nanoporous Glass Synthesis. The silica porous glasses were synthesized from previously reported sol-gel techniques $[13,29,33]$. The silica gels were made from tetraethoxysilane (TEOS) hydrolyzed with distilled water and with ethanol as solvent. The mixture was stirred and aged one week at room temperature. After gelation the alcogels were transformed into xerogels or sintered aerogels.

For the xerogel samples, porosity is partially eliminated by controlled and slow drying [13]. These xerogels samples covered density between 0.5 and $1.6 \mathrm{~g} \cdot \mathrm{cm}^{-3}$.

Some gels are transformed into aerogels by supercritical drying performed at $305^{\circ} \mathrm{C}$ and $13 \mathrm{MPa}$ [29]. The sintering of silica aerogels at high temperature $\left(>1000^{\circ} \mathrm{C}\right)$ has been described previously $[15,26]$. Depending on the duration of the heat treatment, the pores collapse and the bulk density

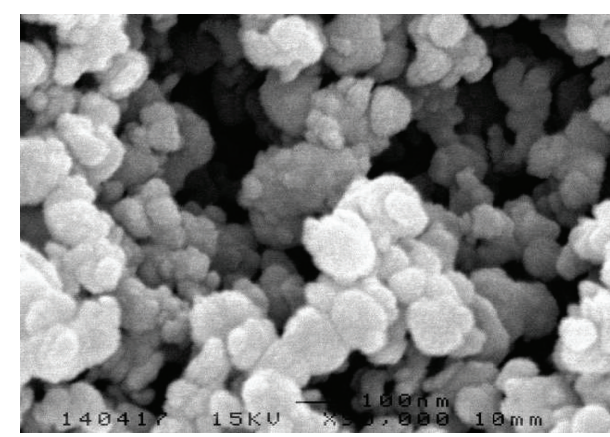

FIGURE 3: Scanning electron microscopy of typical composite aerogel.

increases. These sintered aerogels porosity ranged from $95 \%$ to $0 \%$ (density between 0.1 and $2.2 \mathrm{~g} \cdot \mathrm{cm}^{-3}$ ).

Composite aerogels were synthesized using the same protocol as for previously published ones $[16,33]$. TEOS was hydrolyzed with 15 mole of water $\left(\mathrm{HCl} 10^{-2} \mathrm{M}\right)$ per mole of TEOS for $1 \mathrm{~h}$ under stirring. Pyrogenic silica (aerosil OX 50) was added under stirring. The $\mathrm{pH}$ was adjusted to 4.5 , which led to gelation in a few minutes. The proportion of aerosil with respect to the total silica weight ranged from $5 \%$ to $70 \%$. The composite wet gels were transformed into composite aerogels by supercritical drying with ethanol. The density range is $0.25-0.5 \mathrm{~g} \cdot \mathrm{cm}^{-3}$.

3.2. Experimental Techniques. Bulk density $(\rho)$ was determined from direct measurements of weight and from the geometric dimensions of samples. Porosity $(\phi)$ was calculated from bulk density and skeletal density $\left(\rho_{s}\right)$. The skeletal density, measured by helium pycnometry, was $\rho_{s}=2 \mathrm{~g} / \mathrm{cm}^{3}$ [23].

Elastic modulus $(E)$ and rupture modulus $(\sigma)$ were measured by the three-point bending technique using an Instron 1196 mechanical testing machine ( $24 \mathrm{~N}$ load cell) $[15,28]$.

Toughness $\left(K_{\mathrm{IC}}\right)$ was measured by the Single Edge Notched Beam technique [34] and $a_{c}$ the critical flaw size was calculated from

$$
a_{c}=\frac{\left(K_{\mathrm{IC}} / \sigma\right)^{2}}{1.21 \pi} .
$$

Permeability $(D)$ was measured using a method of impregnation based on Archimedes' principle [8]. The samples are dipped in water and, during impregnation, the thickness of the penetrating water, $h(t)$, increases with time. We previously showed [8] that

$$
D=\frac{\eta \phi h^{2}(t)}{2 \Delta P \cdot t},
$$

where $\Delta P$ is capillary pressure and $\eta$ is water viscosity. We calculated $D$ from the slope of the straight line $h^{2}(t)=f(t)$. $D$ has the dimension of a surface and was expressed in $\mathrm{nm}^{2}$. The details of the technique are given in [16].

Microstructure was analysed by scanning electron microscopy (JEOL 1200EX $100 \mathrm{kV}$ ). A Jeol (JSM-66300F) 


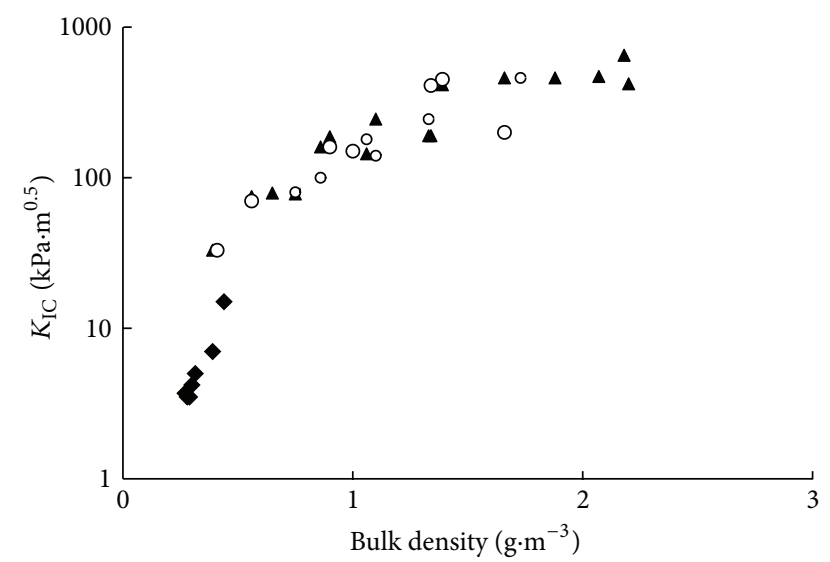

Figure 4: Toughness versus density for xerogels (circles), sintered aerogels (triangles), and composites aerogels (diamonds).

microscope was used to get the back-scattered electron micrographs.

The sintering was characterized by dilatometer (Adamel Lhomargy DI10.2) experiments in the temperature range 25$1300^{\circ} \mathrm{C}$.

The crystalline phases were characterized by X-rays diffraction $(\mathrm{CuK} \alpha)$ with a Phillips PW 1830.

The chemical durability of the glass ceramics was measured with a conventional Soxhlet device [15]. The test was conducted at $100^{\circ} \mathrm{C}$, after 28 days of leaching. The normalized mass loss $\left(\mathrm{g} \cdot \mathrm{m}^{-2}\right)$ was calculated from analysis of the leachates.

\section{Physical Properties of Nanoporous Glasses}

4.1. Mechanical Properties. Figure 4 shows that sintered aerogels, composites aerogels, and xerogels have quite similar toughness. However, sintered aerogels and composite aerogels are capable of resisting filling with an aqueous solution, whereas xerogels are generally not [16]. There are two explanations for these different behaviors: the xerogels network is locally damaged by the stresses that occur during drying. The assumption of damage to the structure is deduced from the reduced stiffness of xerogels compared to composite and sintered aerogels previously measured [35].

The xerogels flaw sizes are almost one order of magnitude higher than the composite and sintered aerogels flaws size (Figure 5). These flaws are created during drying, because of the large shrinkage. Flaws inside the structure act as stress concentrators and capillary stresses are locally amplified by this effect. The second explanation is linked to the smaller mean pore size of the xerogels structure $(10 \mathrm{~nm})$ compared to that of aerogels $(10-100 \mathrm{~nm})$ and composites aerogels (50$200 \mathrm{~nm}$ ). During drying, xerogel is subjected to a compression force that tends to eliminate the larger pores [13]; drying shifts the pore size distribution toward the smaller pores and the capillary forces increase in smaller pores. Larger capillary forces and larger critical flaw sizes explain why the xerogels break during filling with aqueous solution.

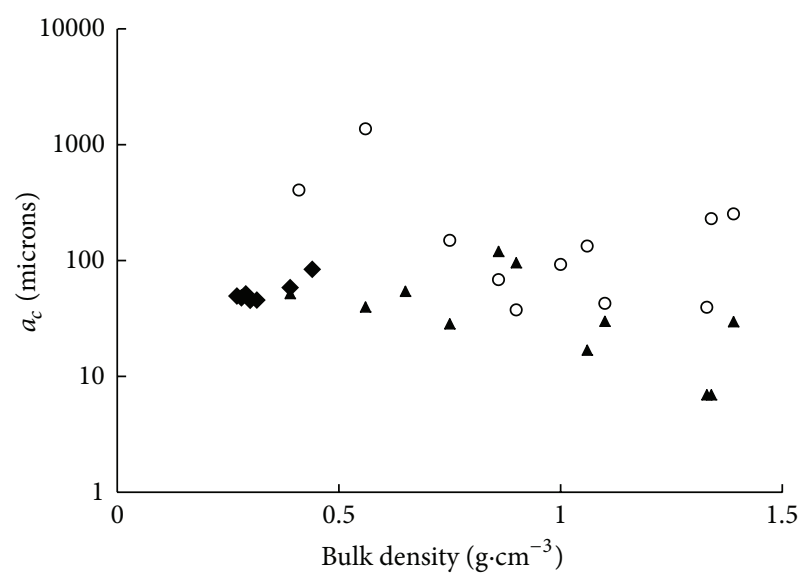

FIGURE 5: Critical flaw size versus density for xerogels (circles), sintered aerogels (triangles), and composites aerogels (diamonds).

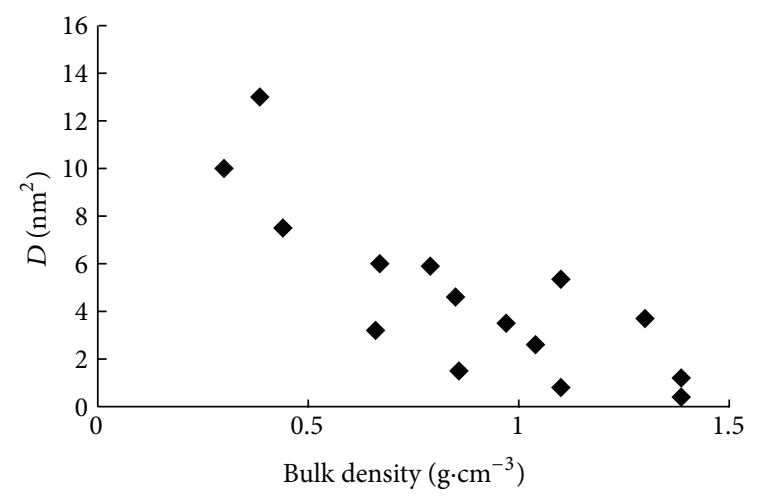

FIGURE 6: Permeability of the sintered aerogels versus the density.

The toughness of the set of sintered aerogels increased by 2 orders of magnitude (Figure 4), over the whole range of density. During the sintering process, densification is induced by viscous flow, which tends to reduce the volume of the whole sample, eliminating the smallest pores $[36,37]$. Because of the mechanical improvement and the elimination of the micropores, the sintered aerogels are able to resist impregnation by a liquid [26].

In the composite approach, it is possible to adjust the pore volume by adding silica powder (such as aerosil) just before gelation $[16,33]$. The addition of aerosil increases bulk density and hence the mechanical properties (Figure 4). Aerosil addition also affects the aggregation process, the pore structure [38], and pore size distribution [33]. It homogenizes the pore structure and increases the mean pore diameter to the mesoporosity range $(50-200 \mathrm{~nm})$ leading to lower capillary forces than in the xerogels.

In conclusion, drying, sintering, and the composite approach will improve the mechanical properties. However, xerogels samples usually cracked during filling with liquids certainly because of the presence of flaws, which weaken the gel network, and the small pores, which enhance capillary forces during filling. We can thus conclude that this set of samples is not an appropriate host for nuclear wastes. 
4.2. Permeability. The second important porous feature of the host matrix is permeability. Permeability $(D)$ was measured by a method based on Archimedes' principle [16]. Previous study has shown that $D$ decreases with sintering [15] and these new results confirm the previous data (Figure 6). The results are in agreement with the empirical Carman-Kozeny relation: $D \propto(1-\rho r) r_{h}{ }^{2}[13,15]$, where $r_{h}$ is the mean pore size (hydraulic radius).

According to this relation, because of the decrease in the mean pore size and the increase in relative density, $D$ decreases. So a compromise in density needs to be found for the use of sintered aerogels as host matrices. Bulk density has to be high enough to obtain a matrix with acceptable mechanical properties but not too high, to have significant permeability. The permeability of the composite aerogels set was measured using the same method (Figure 7) but, in contrast to the sintered aerogels, permeability of composites aerogel increased with an increase in density.

This counterintuitive result (with respect to the CarmanKozeny relation) is due to the fact that while the addition of aerosil particles increases density it also increases mean pore size [33]. The net result is an increase in $D$.

The composite aerogels set combines improvement of the mechanical properties and an increase in permeability. This method is easy to use and produces host matrices with a large porous volume that is accessible and can be rapidly impregnated by water. Next, we tested the different porous networks as host matrices for long lived nuclides.

\section{Loading of Gel Derived Porous Glass by Simulating Oxides}

Although there are a number of fission product radionuclides with high activity $\left({ }^{137} \mathrm{Cs}\right.$ and $\left.{ }^{90} \mathrm{Sr}\right)$ and a long half-life $\left({ }^{99} \mathrm{Tc}\right.$, 200,000 years; ${ }^{129} \mathrm{I}, 1.610^{7}$ years) in nuclear wastes, actinides account for most of the radiotoxicity because, after several hundred years, the radiotoxicity is dominated by ${ }^{239} \mathrm{Pu}$ (halflife $=24,100$ years) and ${ }^{237} \mathrm{~Np}$ (half-life $=2,000,000$ years). Thus, most of the long-term risk is directly related to the fate of these two actinides in the environment. Generally nuclear wastes are provided in salt form in aqueous solutions and, in the trapping approach $[14-17,31]$, the nanopore structure is used to allow migration of the liquid species (salt in solution) throughout the whole porous volume. Because of the fine pore structure, we would expect ourselves to be able to prepare a nanocomposite using a very simple process. Soaking of the porous network by surrogate solutions then needed to be tested. We chose $\mathrm{Nd}$ and Ce because of their different affinity with silica which produces different kinds of glass ceramics, simulating the possible behavior of the actinides in the presence of silica.

In a previous work [15], we showed that partial sintering is required to resist capillary forces, and heat treatment has two effects: it increases the mechanical strength of the aerogels and removes the smallest pores to reduce the effects of capillary phenomena. As explained above, the final density must avoid the formation of cracks but retain a sufficiently large porosity to allow the migration of the liquid through

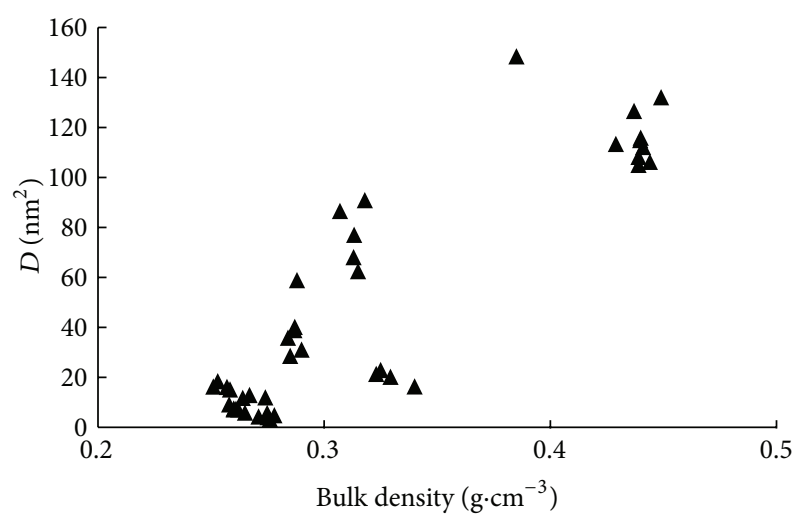

FIGURE 7: Permeability of the composite aerogels versus the density.

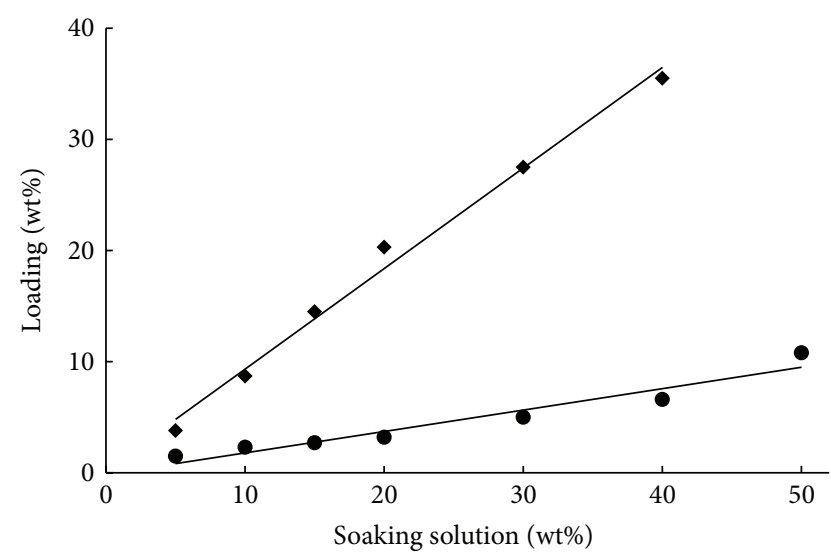

Figure 8: Loading with $\mathrm{Nd}_{2} \mathrm{O}_{3}$ for sintered aerogels (circles) and composite aerogels (diamonds).

the whole volume of the sintered aerogels. The compromise was a bulk density close to $1 \mathrm{~g} \cdot \mathrm{cm}^{-3}$ (almost $50 \%$ of the pore volume). Cerium and neodymium nitrates were dissolved in water. After soaking in an oven the sintered aerogels were dried and calcined at $600^{\circ} \mathrm{C}$ for two hours to decompose the neodymium nitrate. Further heating at $1,100^{\circ} \mathrm{C}$ fully sintered the gel structure $[15,26,39]$.

The dense solid consisted of a silica matrix in which the surrogate oxide was trapped. The difference in weight before soaking and after sintering enables measurement of the "waste loading" in weight percent. Figure 8 shows that waste loading increased with the concentration of the simulate solution. Waste loading close to 10 weight percent can be achieved with this process [15] but the loading was twice lower than expected (calculated from the pore volume and the concentration of the solution). We concluded that, during the preliminary sintering step to achieve density close to $1 \mathrm{~g} \cdot \mathrm{cm}^{-3}$, part of the porosity closed and the soaking solution was unable to invade the whole porosity. Another approach proposed by Aravind et al. [17] is to incorporate surrogate $\left(\mathrm{Nd}_{2} \mathrm{O}_{3}\right)$ in the alcogel just before drying. The results of this study showed that high waste loading was obtained (30\%).

Another way to improve the loading rate is to use a highly permeable porous structure that is more accessible 


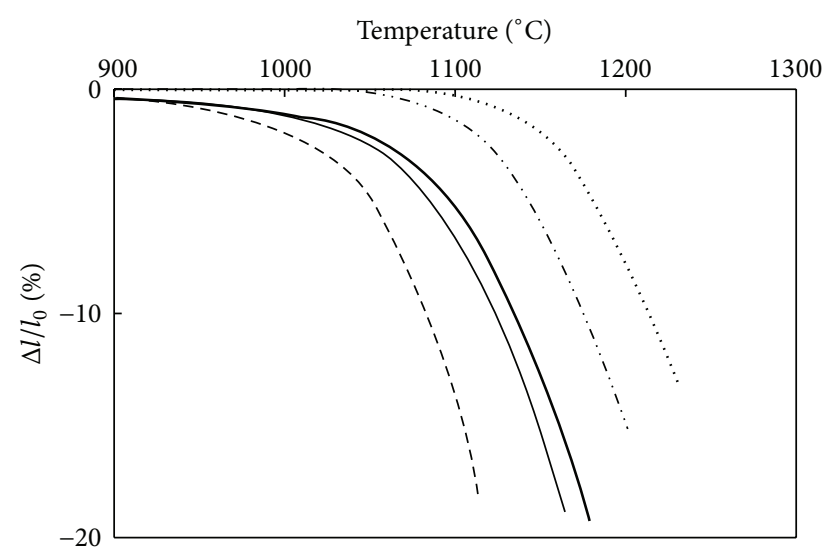

FIGURE 9: Sintering curves of composite aerogels (-- ), loaded with $5 \%(-), 10 \%(-)$, and $13 \% \mathrm{CeO}_{2}(-\cdot \cdot)$; and $13 \% \mathrm{Nd}_{2} \mathrm{O}_{3}(\cdots)$.

to the soaking solutions. This goal was achieved using the composite aerogel set. After soaking, drying, and calcination, the composite aerogels samples were fully sintered in the temperature range $1,100-1,250^{\circ} \mathrm{C}$. Because composite aerogel has a higher pore volume than sintered aerogels, higher waste loading (35\%) can be achieved with this process (Figure 8). However, high surrogate loading should cause thermomechanical stress. We discuss this problem in Section 7 of the paper.

\section{Sintering Behavior}

Dilatometer data (Figure 9) show that the sintering increases rapidly around $1000-1200^{\circ} \mathrm{C}$, in the vicinity of the silica glass transition. Above $1000^{\circ} \mathrm{C}$ the sintering mechanism is a viscous flow process characteristic of amorphous materials $[26,39]$. The sintering process is affected by the loading rate and Figure 9 shows the shrinkage curves of samples loaded with various $\mathrm{CeO}_{2}$ and $\mathrm{Nd}_{2} \mathrm{O}_{3}$ concentrations.

The curves $\left(\Delta l / l_{0}\right)$ show that a high loading increases the temperature range in which shrinkage is large. This temperature is close to $1,050^{\circ} \mathrm{C}$ for the composite aerogel sample without loading, $1150^{\circ} \mathrm{C}$ for the sample containing $10 \%$ of $\mathrm{Nd}_{2} \mathrm{O}_{3}$, and $1,250^{\circ} \mathrm{C}$ for the composite aerogel loaded with $13 \%$ of $\mathrm{Nd}_{2} \mathrm{O}_{3}$.

Loading by surrogate solution prevents sintering, because the crystalline phases $\left(\mathrm{CeO}_{2}\right.$ and $\left.\mathrm{Nd}_{2} \mathrm{O}_{3}\right)$ are not involved in the viscous flow mechanism responsible for sintering of amorphous materials. The effect on the sintering temperature is more pronounced for $\mathrm{Nd}$ than for Ce because the samples loaded with $\mathrm{Nd}$ present three different crystalline phases: neodymium mono-silicate $\left(\mathrm{Nd}_{2} \mathrm{SiO}_{5}\right)$, di-silicate $\left(\mathrm{Nd}_{2} \mathrm{Si}_{2} \mathrm{O}_{7}\right)$, and neodymium sesquioxide $\left(\mathrm{Nd}_{2} \mathrm{O}_{3}\right)$. Consequently the sintering step has to be adjusted to the composition of the loaded porous glass and can vary by $200^{\circ} \mathrm{C}$.

\section{Characterization of the Waste Glass Ceramics}

We have shown that these porous matrices can be filled with the surrogate solution and fully sintered, demonstrating that

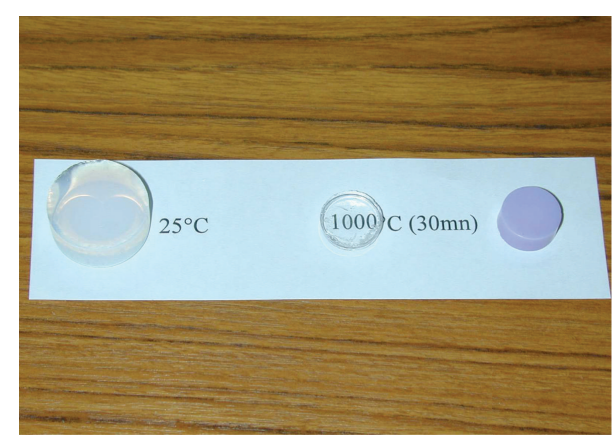

Figure 10: Aerogels sample (left), sintered aerogel (middle), and Nd loaded material (right).

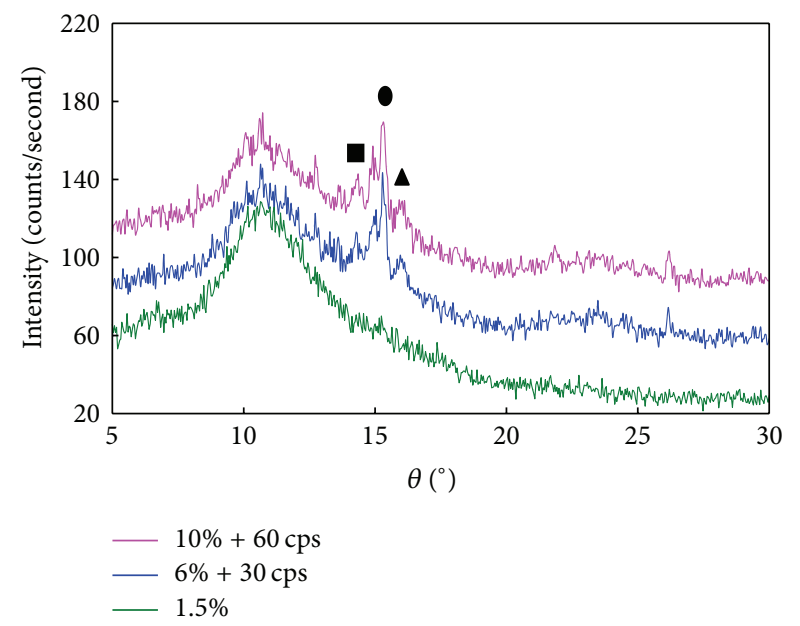

FIGURE 11: X-ray spectra of the $\left(\mathrm{SiO}_{2}-\mathrm{Nd}_{2} \mathrm{O}_{3}\right)$ glass ceramic: $\mathrm{Nd}_{2} \mathrm{SiO}_{5}$ (triangle), $\mathrm{Nd}_{2} \mathrm{Si}_{2} \mathrm{O}_{7}$ (square), and $\mathrm{Nd}_{2} \mathrm{O}_{3}$ (circle).

rapid containment of actinides in silica is possible. After sintering, the nanocomposite solids consist of a silica matrix in which the actinide surrogate is trapped. The waste loadings we studied are in the range of 5-35\% but loading higher than $50 \%$ can be achieved with these processes $[17,31]$.

7.1. Structure. Figure 10 shows an aerogel on the left. After complete sintering the aerogel is transformed in silica glass (middle) or in glass ceramic (right).

The final structure of the nanocomposite materials is that of glass ceramics. The X-ray spectra show that the sintered material loaded with $\mathrm{Ce}$ is a biphasic compound $\left(\mathrm{SiO}_{2}-\right.$ $\mathrm{CeO}_{2}$ ) [40]. The sample loaded with $\mathrm{Nd}$ presents three different crystalline phases, neodymium mono-silicate $\left(\mathrm{Nd}_{2} \mathrm{SiO}_{5}\right)$ and di-silicate $\left(\mathrm{Nd}_{2} \mathrm{Si}_{2} \mathrm{O}_{7}\right)$ but also neodymium sesquioxide $\left(\mathrm{Nd}_{2} \mathrm{O}_{3}\right)$ (Figures 11 and 12).

High $\mathrm{Nd}$ content favors the presence of neodymium mono-silicate $\left(\mathrm{Nd}_{2} \mathrm{SiO}_{5}\right)$. These structural differences are the result of the affinity of $\mathrm{Ce}$ and $\mathrm{Nd}$ for $\mathrm{Si}$. In the case of $\mathrm{Ce}$, the formation of a binary glass in a melting process is difficult; Ce generally forms $\mathrm{CeO}_{2}$ crystallites [41]. Moreover the crystalline phases of cerium silicates like $\mathrm{Ce}_{2} \mathrm{Si}_{2} \mathrm{O}_{7}$ are not stable at temperatures below $1,400^{\circ} \mathrm{C}[42,43]$. 


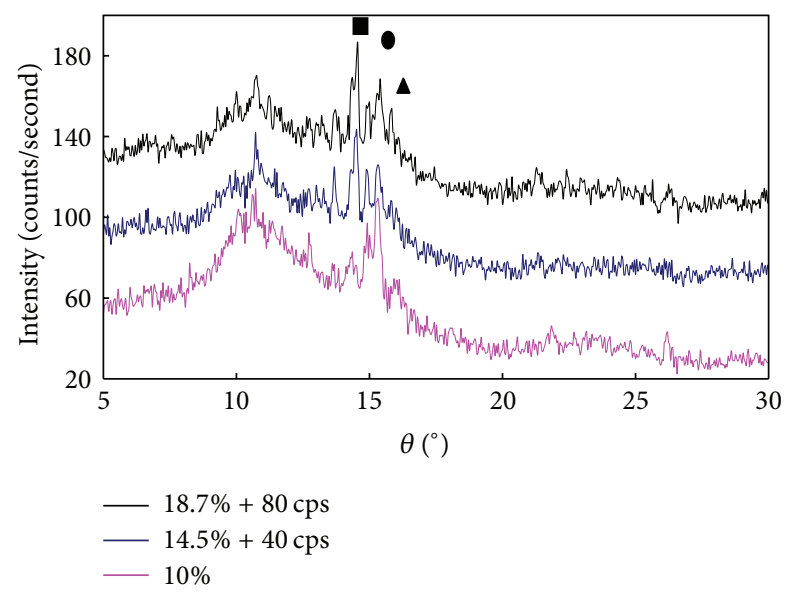

Figure 12: X-ray spectra of the $\left(\mathrm{SiO}_{2}-\mathrm{Nd}_{2} \mathrm{O}_{3}\right)$ glass ceramic: $\mathrm{Nd}_{2} \mathrm{SiO}_{5}$ (triangle), $\mathrm{Nd}_{2} \mathrm{Si}_{2} \mathrm{O}_{7}$ (square), and $\mathrm{Nd}_{2} \mathrm{O}_{3}$ (circle).

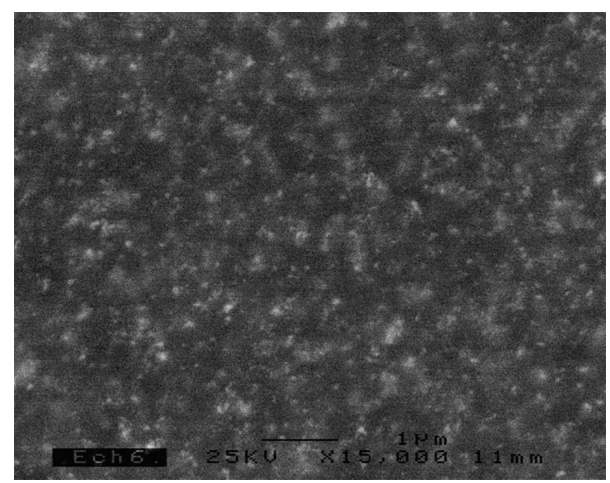

FIGURE 13: Back-scattered electron microscopy of the glass ceramic loaded with of $\mathrm{Nd}_{2} \mathrm{O}_{3}$.

In the case of $\mathrm{Nd}$, glasses with a weight percent between 2 and 5 have been obtained [44, 45]. The phase diagram also shows that the different $\mathrm{Nd}$ silicates $\left(\mathrm{Nd}_{2} \mathrm{SiO}_{5}\right.$ and $\left.\mathrm{Nd}_{2} \mathrm{Si}_{2} \mathrm{O}_{7}\right)$ are stable at room temperature $\left(\mathrm{Nd}_{2} \mathrm{O}_{3}\right)[46,47]$.

7.2. Electron Microscopy. Back-scattered electron microscopy (Figures 13 and 14) showed that the surrogate oxides were homogeneously distributed in the silica matrix.

The size of the surrogate domain ranged from 20 to $200 \mathrm{~nm}$ and the nanocomposites consisted of a silica matrix in which lanthanides oxides are trapped.

7.3. Thermomechanical Properties. The mechanical properties of the different glass ceramics are important in validating the process. The mechanical behavior of matrices containing nuclear wastes should be as high as possible because fracturing of the matrix will increase the corrosion rate (i.e., increase the contact surface between the solid and water). The rupture strength decreases progressively with the $\mathrm{Nd}$ loading and the weakening is important when Ce loading is higher than 10$15 \%$ [48]. Figure 15 compares the experimental data of the elastic modulus with calculated data given by the Reuss model [49].

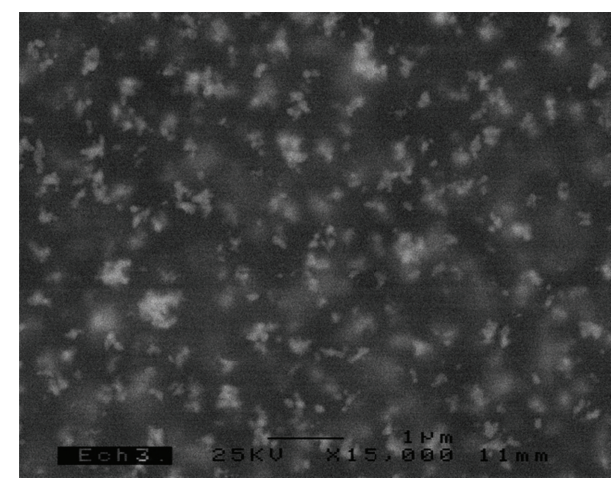

FIGURE 14: Back-scattered electron microscopy of the glass ceramic loaded with of $\mathrm{CeO}_{2}$.

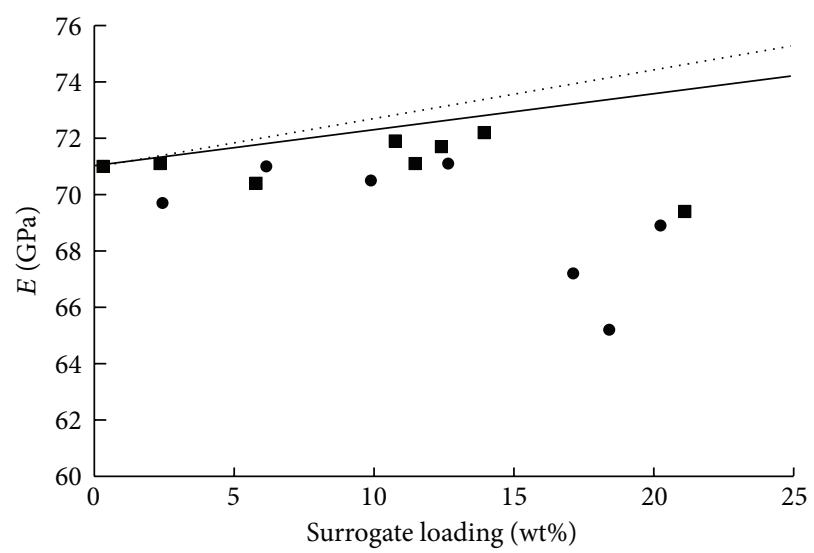

FIGURE 15: Evolution of the elastic modulus versus the loading rate for $\mathrm{Nd}_{2} \mathrm{O}_{3}$ (square), $\mathrm{CeO}_{2}$, (circle) and Reuss models or $\mathrm{Nd}_{2} \mathrm{O}_{3}$ (dotted line) and $\mathrm{CeO}_{2}$ (full line).

The model predicts the evolution of Young's modulus of composite materials as a function of the volume fraction and elastic properties of the different phases. The model assumes the stresses are transferred from a phase to another which requires both a close contact between matrix and particles and no microcracking. The model straight line was calculated with the elastic moduli of the silica glass (73 GPa [50]), $\mathrm{CeO}_{2}$ (184 GPa [51]), and $\mathrm{Nd}_{2} \mathrm{O}_{3}(418 \mathrm{GPa}$ [52]). Figure 15 shows that for loading higher than $15 \%$ the experimental data are clearly lower than the model prediction which confirms a weakening of the composite structure. This weakening of the material is the result of the large differences between the thermal expansion coefficients of the compounds present in the glass ceramics; the thermal expansion coefficient of vitreous silica $\left(0.510^{-6} /{ }^{\circ} \mathrm{C}\right)$ is lower than that of $\mathrm{CeO}_{2}\left(11.510^{-6} /{ }^{\circ} \mathrm{C}\right)$ and $\mathrm{Nd}_{2} \mathrm{O}_{3}\left(1210^{-6} /{ }^{\circ} \mathrm{C}\right)$ crystallites [47]. After sintering and cooling, local stresses can occur at the boundary of the $\mathrm{CeO}_{2}$ and $\mathrm{Nd}_{2} \mathrm{O}_{3}$ crystallites because of major differences in thermomechanical properties. The net result is the formation of microcracks that weaken the glass ceramics. Some authors tried to improve waste loading between 20 and 50\% [17, 31]. However this approach could lead to microcracks in glass ceramics and the microflaws would encourage aqueous 
TABle 1: Normalized Ce, Nd, and Si mass loss $\left(\mathrm{g} \cdot \mathrm{m}^{-2}\right)$ versus corrosion time.

\begin{tabular}{lccccc}
\hline Days & $\begin{array}{c}\mathrm{SiO}_{2} \\
\mathrm{Si} \mathrm{mass} \mathrm{loss} \\
\left(\mathrm{g} \cdot \mathrm{m}^{-2}\right)\end{array}$ & $\begin{array}{c}\mathrm{SiO}_{2}-\mathrm{CeO}_{2} \\
\mathrm{Si} \mathrm{mass} \mathrm{loss} \\
\left(\mathrm{g} \cdot \mathrm{m}^{-2}\right)\end{array}$ & $\begin{array}{c}\mathrm{SiO}_{2}-\mathrm{CeO}_{2} \\
\mathrm{Ce} \text { mass loss } \\
\left(\mathrm{g} \cdot \mathrm{m}^{-2}\right)\end{array}$ & $\begin{array}{c}\mathrm{SiO}_{2}-\mathrm{Nd}_{2} \mathrm{O}_{3} \\
\mathrm{Si} \mathrm{mass} \mathrm{loss} \\
\left(\mathrm{g} \cdot \mathrm{m}^{-2}\right)\end{array}$ & $\begin{array}{c}\mathrm{SiO}_{2}-\mathrm{Nd}_{2} \mathrm{O}_{3} \\
\mathrm{Nd} \text { mass loss } \\
\left(\mathrm{g} \cdot \mathrm{m}^{-2}\right)\end{array}$ \\
\hline 7 & 0.124 & 0.250 & n.m. & 1.17 & 0.01 \\
14 & 0.252 & 0.436 & n.m. & 2.89 & 0.025 \\
21 & 0.34 & 0.656 & 0.108 & 5.91 & 0.15 \\
28 & 0.442 & 1.012 & 0.162 & 9.33 & 0.31 \\
\hline
\end{tabular}

corrosion and hence lead to the diffusion of actinides in the environment. Once again a compromise needs to be found for "efficient" waste loading in the range $10-15 \%$. This loading rate is acceptable and corresponds to the nuclear waste content in existing borosilicate nuclear waste glass $[10,52]$.

7.4. Chemical Durability. Chemical durability ensures resistance to aqueous corrosion. In general, glass corrosion in aqueous solutions is governed by diffusion-controlled ion exchange and dissolution of the glass network itself [52-55]. Corrosion could be favored by the presence of thermomechanical stresses [55] and by the solubility of the silica in regions with different curvature [56]. Moreover saturation of the solution can affect the processes. We have seen that the $\mathrm{Nd}$ glass ceramic have a more complicated structure than Ce glass ceramic. As a result, different chemical durability behaviors are to be expected.

As explained in the introduction, vitreous silica has high chemical durability. This is thus necessary to compare the mechanisms of alteration of the $\mathrm{Nd}$ and Ce glass ceramics with those of silica and the usual borosilicate glass. The chemical durability of the glass ceramics was measured with a conventional Soxhlet device [15], and we measured the Ce, Nd, and Si mass losses [40] (Table 1).

The normalized silica loss characterizes the destruction of the glass network by the glass former dissolution. The dynamic corrosion rate $\left(V_{0}\right)$ of pure silica is equal to $0.015 \mathrm{~g} \cdot \mathrm{m}^{-2}$ per day, 100 times lower than the corrosion rate of the usual nuclear waste glass for which $V_{0}$ is equal to $2 \mathrm{~g} \cdot \mathrm{m}^{-2}$ per day $[53,54] . V_{0}$ for the glass ceramics loaded with the Ce was $0.035 \mathrm{~g} \cdot \mathrm{m}^{-2}$ per day and $0.25 \mathrm{~g} \cdot \mathrm{m}^{-2}$ per day with $\mathrm{Nd}$ : evidence of the better chemical durability of glass ceramics compared to that of nuclear waste glass. The corrosion rate of the $\mathrm{Nd}$ glass ceramic is 8 times higher than $\mathrm{SiO}_{2}$. It has been shown that the sol-gel-glass process allows the synthesis of binary neodymium silica glasses with neodymium content as high as $5 \%[44,45]$, less durable than $\mathrm{SiO}_{2}$.

Long-term aqueous corrosion results [48] also suggest that in these new matrices a limit of solubility is attained that prevents alteration of the material, which is not the case of standard nuclear waste glass in which the process of corrosion is never stopped in water $[8,57,58]$. In the literature, the corrosion of the $\mathrm{Nd}$ glass ceramics has also been studied through soxhlet experiments $[9,23]$. These authors also found a poor corrosion effect but unfortunately the data are not comparable because of the lower temperature they used for the process $\left(60-70^{\circ} \mathrm{C}\right)$ and a shorter experiment (only lasting two days) which does not allow the chemical durability to be characterized in saturation conditions.

\section{Conclusion}

Borosilicate glass is a solid in which a wide range of nuclear waste can be dissolved and successful industrial-scale technologies have been developed. However research is now investigating new containment matrices with high chemical durability, because it is important to limit the possible release of radionuclides if the matrix is destroyed by aqueous erosion. This paper describes different matrices aimed at rendering hazardous materials less dangerous including fixing the hazardous material in the nanopores of porous glasses and vitrifying the nanoporous material containing the less hazardous material.

The composite silica approach is likely the best compromise to confine actinides. A high pore volume is available for impregnation and network permeability is increased and rapid containment of surrogate actinide oxides in silica has been demonstrated. Surrogate elements are embedded in the silica matrix. The main advantages of the process are the high chemical durability of the silica matrix and the good mechanical resistance.

In addition to the problem of the synthesis of new porous matrices, the influence of the reactivity of the surface and of the pore structure on the physical and chemical properties of the invading species is the subject of much ongoing research. We have presented two examples in which the reactivity of the chemical species in the matrix is extremely important for the physical properties of the final two-phase materials. It should also be underlined that this process enables the synthesis of nanocomposite materials, which cannot be achieved by melting. Sintering preserves the initial heterogeneous structure.

\section{Competing Interests}

The authors declare that they have no competing interests.

\section{References}

[1] F. P. Glasser, "The role of ceramics, cement and glass in the immobilization of radioactive wastes," British Ceramic Transactions, vol. 84, pp. 1-8, 1985.

[2] I. W. Donald, B. L. Metcalfe, and R. N. J. Taylor, "The immobilization of high level radioactive wastes using ceramics and glasses," Journal of Materials Science, vol. 32, no. 22, pp. 58515887, 1997. 
[3] V. M. Oversby and A. E. Ringwood, "Leaching studies on synroc AT $95^{\circ} \mathrm{C}$ and $200^{\circ} \mathrm{C}$," Radioactive Waste Management, vol. 2, no. 3, pp. 223-237, 1982.

[4] G. R. Lumpkin and R. C. Ewing, "Geochemical alteration of pyrochlore group minerals: pyrochlore subgroup," American Mineralogist, vol. 80, no. 7-8, pp. 732-743, 1995.

[5] P. J. McGlin, K. P. Hart, E. H. Loi, and E. R. Vance, "Ph dependence of the aqueous dissolution rates of perovskite and zirconolite at $90^{\circ} \mathrm{C}, "$ Materials Research Society Symposium Proceedings, vol. 353, pp. 847-854, 1995.

[6] P. J. Hayward, "The use of glass ceramics for immobilising high level wastes from nuclear fuel recycling," Glass Technology, vol. 29, no. 4, pp. 122-136, 1988.

[7] P. Loiseau, D. Caurant, N. Baffier, L. Mazerolles, and C. Fillet, "Development of zirconolite-based glass-ceramics for the conditioning of actinides," in Scientific Basis for Nuclear Waste Management XXIV, K. P. Hart and G. P. Lumpkin, Eds., vol. 663 of MRS Proceedings, pp. 179-189, Materials Research Society, Warrendale, Pa, USA, 2001.

[8] P. Frugier, C. Martin, I. Ribet, T. Advocat, and S. Gin, "The effect of composition on the leaching of three nuclear waste glasses: R7T7, AVM and VRZ,' Journal of Nuclear Materials, vol. 346, no. 2-3, pp. 194-207, 2005.

[9] R. C. Ewing, "Nuclear waste form glasses: the evaluation of very long term behaviour," Materials Technology: Advanced Performance Materials, vol. 16, pp. 30-36, 2001.

[10] N. Jacquet-Francillon, R. Bonniaud, and C. Sombret, "Glass as a material for the final disposal of fission products," Radiochimica Acta, vol. 25, no. 3-4, pp. 231-240, 1978.

[11] V. M. Oversby and A. E. Ringwood, "Leaching studies on synroc at $95 \circ \mathrm{C}$ and 200॰C," Radioactive Waste Management, vol. 2, no. 3, pp. 223-237, 1982.

[12] I. W. Donald, B. L. Metcalfe, and R. N. J. Taylor, "The immobilization of high level radioactive wastes using ceramics and glasses," Journal of Materials Science, vol. 32, no. 22, pp. 58515887, 1997.

[13] J. F. Brinker and G. W. Scherer, Sol-Gel Science, Academic Press, New York, NY, USA, 1990.

[14] J. H. Simmons, P. B. Macedo, A. Barkatt, and T. A. Litovitz, "Fixation of radioactive waste in high silica glasses," Nature, vol. 278, no. 5706, pp. 729-731, 1979.

[15] T. Woignier, J. Reynes, J. Phalippou, J. L. Dussossoy, and N. Jacquet-Francillon, "Sintered silica aerogel: a host matrix for long life nuclear wastes," Journal of Non-Crystalline Solids, vol. 225, pp. 353-357, 1998.

[16] J. Reynes, T. Woignier, and J. Phalippou, "Permeability measurement in composite aerogels: application to nuclear waste storage," Journal of Non-Crystalline Solids, vol. 285, no. 1-3, pp. 323-327, 2001.

[17] P. R. Aravind, L. Sithara, P. Mukundan, P. Krishna Pillai, and K. G. K. Warrier, "Silica alcogels for possible nuclear waste confinement-a simulated study," Materials Letters, vol. 61, no. 11-12, pp. 2398-2401, 2007.

[18] A. Deptula, M. Milkowska, W. Lada et al., "Sol-gel processing of silica nuclear wastes glasses," New Journal of Glass and Ceramics, vol. 1, no. 3, pp. 105-111, 2011.

[19] G. W. Scherer, "Sintering of low density glasses: experimental study," Journal of the American Ceramic Society, vol. 60, no. 5-6, pp. 239-243, 1977.

[20] P. F. James, "The gel to glass transition: chemical and microstructural evolution," Journal of Non-Crystalline Solids, vol. 100, no. 1-3, pp. 93-114, 1988.
[21] J. G. Zwissler and M. A. Adams, Fracture Mechanics of Ceramics, Edited by R. C. Bradt, A. G. Evans, D. P. H. Hasselman and F. F. Lange, Plenum Press, New York, NY, USA, 1983.

[22] F. Pernot, P. Baldet, F. Bonnel, J. Zarzycki, and P. Rabischong, "Development of phosphate glass-ceramics for bone implants," Ceramics International, vol. 9, no. 4, pp. 127-131, 1983.

[23] P. Debye and R. L. Cleland, "Flow of liquid hydrocarbons in porous vycor," Journal of Applied Physics, vol. 30, no. 6, pp. 843$849,1959$.

[24] K. Kuhne and W. Skatulla, "Physikalische und chemische Untersuchungen an Gläsern,” Silikattechn, vol. 10, pp. 105-119, 1959.

[25] T. Elmer H, "Porous and reconstructed glasses," in Engineered Materials Handbook, vol. 4, pp. 427-432, ASM International, Materials Park, Ohio, USA, 1992.

[26] T. Woignier, J. Phalippou, and M. Prassas, "Glasses from aerogels-part 2 the aerogel-glass transformation," Journal of Materials Science, vol. 25, no. 7, pp. 3118-3126, 1990.

[27] E. D. Zanotto, "The formation of unusual glasses by sol-gel processing," Journal of Non-Crystalline Solids, vol. 147-148, pp. 820-823, 1992.

[28] T. Woignier, J. Phalippou, H. Hdach, G. Larnac, F. Pernot, and G. W. Scherer, "Evolution of mechanical properties during the alcogel-aerogel-glass process," Journal of Non-Crystalline Solids, vol. 147-148, pp. 672-680, 1992.

[29] J. Phalippou, T. Woignier, and M. Prassas, "Glasses from aerogels-part 1: the synthesis of monolithic silica aerogels," Journal of Materials Science, vol. 25, no. 7, pp. 3111-3117, 1990.

[30] J. L. Gurav, I.-K. Jung, H.-H. Park, E. S. Kang, and D. Y. Nadargi, "Silica aerogel: synthesis and applications," Journal of Nanomaterials, vol. 2010, Article ID 409310, 11 pages, 2010.

[31] P. R. Aravind, P. Shajesh, P. Mukundan, P. Krishna Pillai, and K. G. K. Warrier, "Non-supercritically dried silica-silica composite aerogel and its possible application for confining simulated nuclear wastes," Journal of Sol-Gel Science and Technology, vol. 46, no. 2, pp. 146-151, 2008.

[32] R. Sempere, D. Bourret, T. Woignier, J. Phalippou, and R. Jullien, "Scaling theory and numerical applications of aerogel sintering," Physical Review Letters, vol. 71, no. 20, pp. 3307-3312, 1993.

[33] M. Toki, S. Miyashita, T. Takeuchi, S. Kanbe, and A. Kochi, "A large-size silica glass produced by a new sol-gel process," Journal of Non-Crystalline Solids, vol. 100, no. 1-3, pp. 479-482, 1988.

[34] S. Sakka and T. Adachi, "Stability of sol-gel derived porous silica monolith to solvents," Journal of Materials Science, vol. 25, no. 7, pp. 3408-3414, 1990.

[35] G. W. Scherer, D. M. Smith, X. Qiu, and J. M. Anderson, "Compression of aerogels," Journal of Non-Crystalline Solids, vol. 186, pp. 316-320, 1995.

[36] G. W. Scherer, "Sintering of low-density glasses: I. Theory," Journal of the American Ceramic Society, vol. 60, no. 5-6, pp. 236-239, 1977.

[37] T. Woignier, J. Phalippou, J. Quinson F, M. Pauthe, M. RepellinLacroix, and G. W. Scherer, "The sintering of silica aerogels studied by thermoporometry," Journal of Sol-Gel Science and Technology, vol. 2, no. 1, pp. 277-281, 1994.

[38] C. Marlière, T. Woignier, P. Dieudonné, J. Primera, M. Lamy, and J. Phalippou, "Two fractal structures in aerogel," Journal of Non-Crystalline Solids, vol. 285, no. 1-3, pp. 175-180, 2001.

[39] W. G. Scherer, "Sintering of low density glasses: II experimental study," Journal of the American Ceramic Society, vol. 60, pp. 239243, 1977. 
[40] T. Woignier, J. Reynes, J. Phalippou, and J. L. Dussossoy, "Nuclear waste storage in gel-derived materials," Journal of SolGel Science and Technology, vol. 19, no. 1-3, pp. 833-837, 2000.

[41] R. G. Haire, Z. Assefa, and N. Stump, "Fundamental science of elements in selected immobilization glasses: significance for TRU disposal schemes," Materials Research Society Symposium Proceeding V, vol. 506, pp. 153-160, 1998.

[42] J. Felsche and W. Hirsiger, "The polymorphs of the rare-earth pyrosilicates R.E..$_{2} \mathrm{Si}_{2} \mathrm{O}_{7}$, [R.E.: La, Ce, $\mathrm{Pr}, \mathrm{Nd}, \mathrm{Sm}$ ], Journal of the Less-Common Metals, vol. 18, no. 2, pp. 131-137, 1969.

[43] H. A. M. Van Hal and H. T. Hintzen, "Compound formation in the $\mathrm{Ce}_{2} \mathrm{O}_{3}-\mathrm{SiO}_{2}$ system," Journal of Alloys and Compounds, vol. 179, no. 1-2, pp. 77-85, 1992.

[44] I. M. Thomas, S. A. Payne, and G. D. Wilke, "Optical properties and laser demonstrations of Nd-doped sol-gel silica glasses," Journal of Non-Crystalline Solids, vol. 151, no. 3, pp. 183-194, 1992.

[45] E. J. A. Pope and J. D. Mackenzie, "Sol-gel processing of neodymia-silica glass," Journal of the American Ceramic Society, vol. 76, no. 5, pp. 1325-1328, 1993.

[46] R. O. Miller and D. E. Rase, "Phase equilibrium in the system $\mathrm{Nd}_{2} \mathrm{O}_{3}-\mathrm{SiO}_{2}$," Journal of the American Ceramic Society, vol. 47, no. 12, pp. 65-654, 1964.

[47] N. A. Toropov, "Determination of phase diagrams using diffusion techniques," in Proceedings of the Transactions of the 7th International Ceramic Congress, pp. 435-442, London, UK, 1960.

[48] T. Woignier, J. Reynes, and J. Phalippou, "Sintering of silica aerogels for glass synthesis: application to nuclear waste containment," in Aerogels Handbook, M. A. Aegerter, N. Leventis, and M. M. Koebel, Eds., Advances in Sol-Gel Derived Materials and Technologies, chapter 29, pp. 665-680, Springer, New York, NY, USA, 2011.

[49] I. Warshaw and R. Roy, "Thermal-expansion measurements from nonindexed high-temperature X-ray powder patterns," Journal of the American Ceramic Society, vol. 44, no. 8, pp. 421422, 1961.

[50] N. P. Bansal and D. R. Doremus, Handbook of Glass Properties, Academic Press, New York, NY, USA, 1986.

[51] E. Keler and A. B. Andreeva, "Stabilization of zirconia with comnbinded additives and a study of a solid solution staility," Ogneupory, vol. 5, pp. 224-230, 1963.

[52] L. Werme, I. K. Björner, G. Bart et al., "Chemical corrosion of highly radioactive borosilicate nuclear waste glass under simulated repository conditions," Journal of Materials Research, vol. 5, no. 5, pp. 1130-1146, 1990.

[53] W. Lutze, G. Malow, R. C. Ewing, M. J. Jercinovic, and K. Keil, "Alteration of basalt glasses: implications for modelling the long-term stability of nuclear waste glasses," Nature, vol. 314, no. 6008, pp. 252-255, 1985.

[54] J. L. Nogues, Les mécanismes de corrosion des verres de confinement des produits de fission [Ph.D. thesis], Université de Montpellier, Montpellier, France, 1984.

[55] B. C. Bunker, "Molecular mechanisms for corrosion of silica and silicate glasses," Journal of Non-Crystalline Solids, vol. 179, pp. 300-308, 1994.

[56] R. K. Iler, The Chemistry of Silica, John Wiley \& Sons, New York, NY, USA, 1979.

[57] B. Grambow, "A general rate equation for nuclear waste glass corrosion," Materials Research Society Symposium Proceedings, vol. 44, pp. 15-21, 1985.
[58] J.-C. Petit, J.-C. Dran, G. D. Mea, and A. Paccagnella, "Dissolution mechanisms of silicate minerals yielded by intercomparison with glasses and radiation damage studies," Chemical Geology, vol. 78, no. 3-4, pp. 219-227, 1989. 

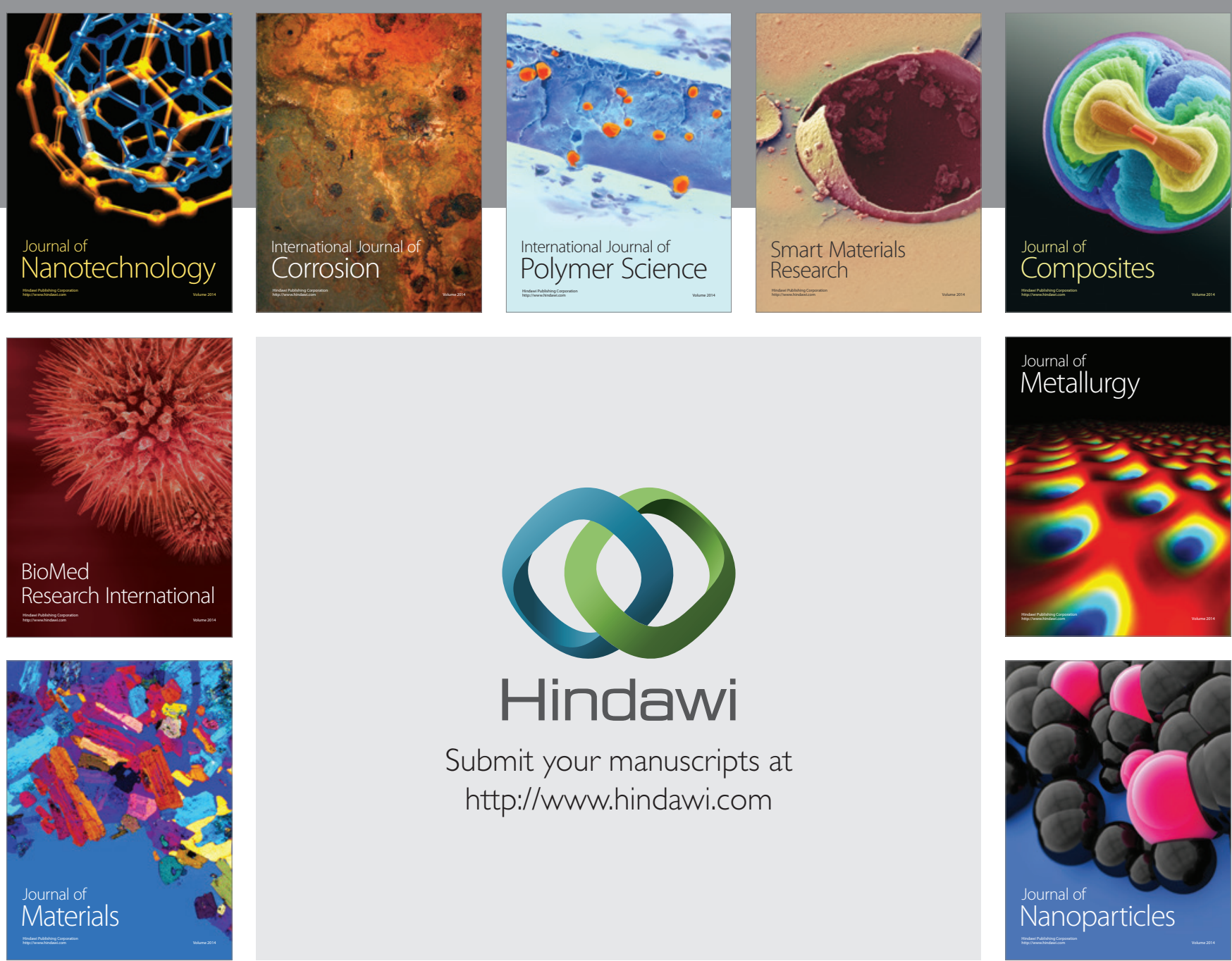

\section{Hindawi}

Submit your manuscripts at

http://www.hindawi.com

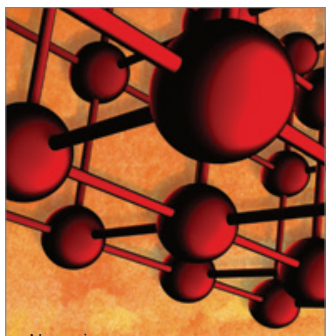

Materials Science and Engineering
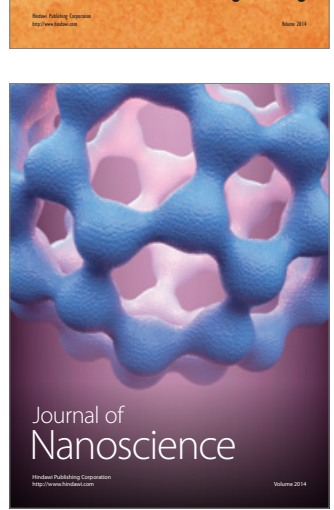
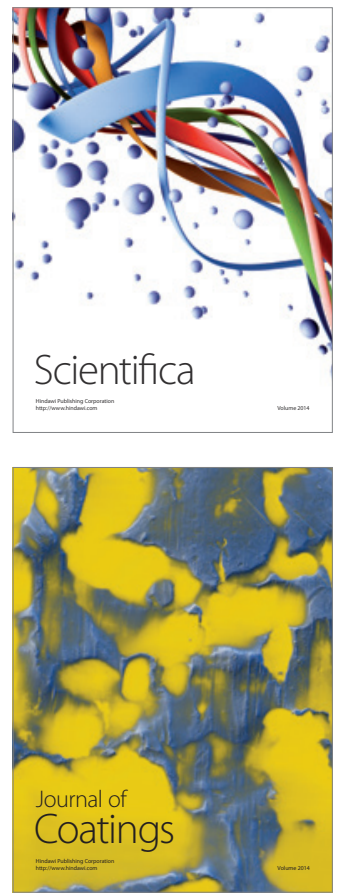
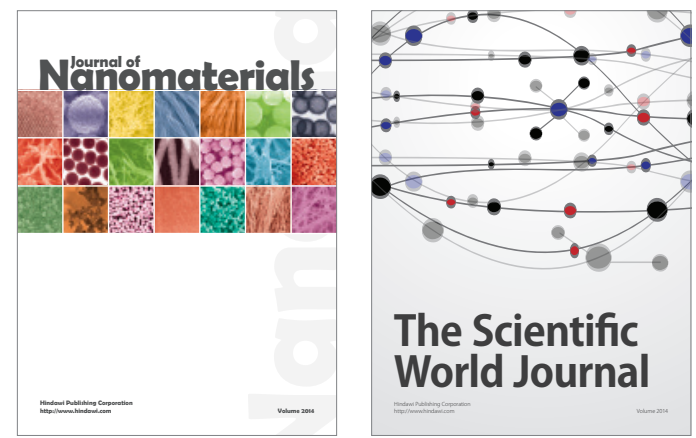

The Scientific World Journal
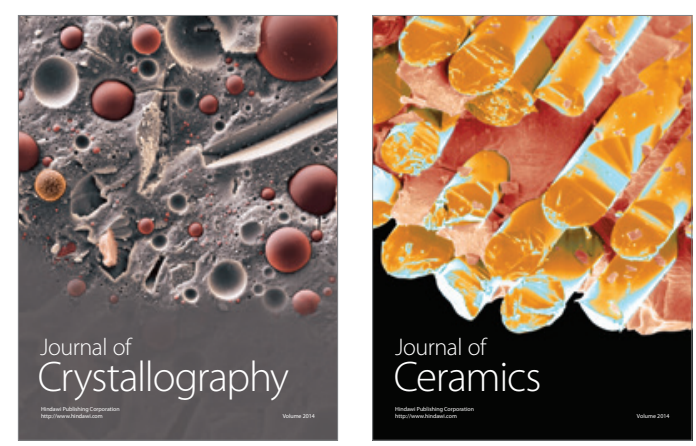
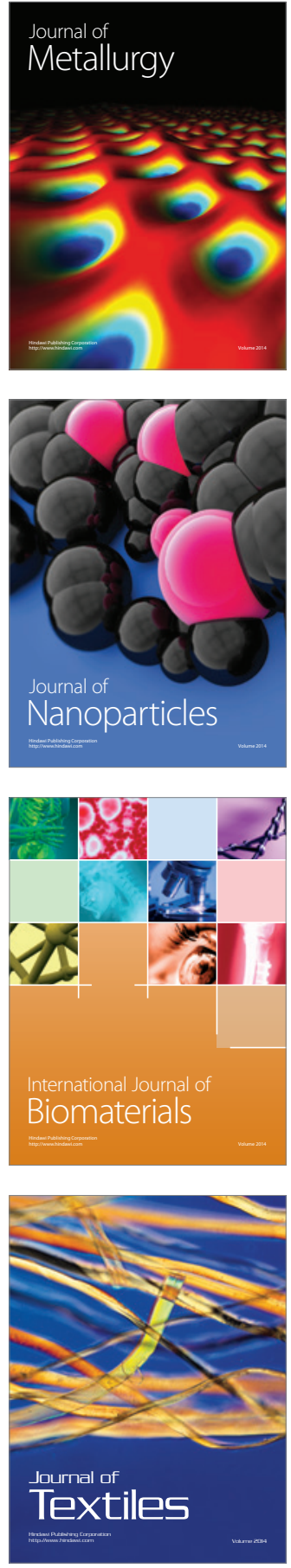